\title{
Effects of grazing on leaf traits and ecosystem functioning in Inner Mongolia grasslands: scaling from species to community
}

\author{
S. X. Zheng ${ }^{1}$, H. Y. Ren ${ }^{1}$, Z. C. Lan ${ }^{1}$, W. H. Li ${ }^{1}$, K. B. Wang ${ }^{2}$, and Y. F. Bai ${ }^{1}$ \\ ${ }^{1}$ State Key Laboratory of Vegetation and Environmental Change, Institute of Botany, Chinese Academy of Sciences, \\ Beijing 100093, China \\ ${ }^{2}$ State Key Laboratory of Soil Erosion and Dryland Farming on the Loess Plateau, Institute of Soil and Water Conservation, \\ Chinese Academy of Sciences, Yangling, Shaanxi 712100, China
}

Received: 19 August 2009 - Published in Biogeosciences Discuss.: 16 October 2009

Revised: 26 February 2010 - Accepted: 15 March 2010 - Published: 26 March 2010

\begin{abstract}
Understanding the mechanistic links between environmental drivers, human disturbance, plant functional traits, and ecosystem properties is a fundamental aspect of biodiversity-ecosystem functioning research. Recent studies have focused mostly on leaf-level traits or communitylevel weighted traits to predict species responses to grazing and the consequent change in ecosystem functioning. However, studies of leaf-level traits or community-level weighted traits seldom identify the mechanisms linking grazing impact on leaf traits to ecosystem functioning. Here, using a multi-organization-level approach, we examined the effects of grazing on leaf traits (i.e., leaf area, leaf dry mass and specific leaf area) and ecosystem functioning across six communities of three vegetation types along a soil moisture gradient in the Xilin River Basin of Inner Mongolia grassland, China. Our results showed that the effects of grazing on leaf traits differed substantially when scaling up from leaf-level to species, functional group (i.e., life forms and water ecotype types), and community levels; and they also varied with vegetation type or site conditions. The effects of grazing on leaf traits diminished progressively along the hierarchy of organizational levels in the meadow, whereas the impacts were predominantly negative and the magnitude of the effects increased considerably at higher organizational levels in the typical steppe. Soil water and nutrient availability, functional trade-offs between leaf size and number of leaves per individual, and differentiation in avoidance and tolerance strategies among coexisting species are likely to be responsible for the observed responses of leaf traits to grazing at different levels of organization and among vegetation types. Our find-
\end{abstract}

Correspondence to: Y. F. Bai

(yfbai@ibcas.ac.cn) ings also demonstrate that, at both the functional group and community levels, standing aboveground biomass increased with leaf area and specific leaf area. Compared with the large changes in leaf traits and standing aboveground biomass, the soil properties were relatively unaffected by grazing. Our study indicates that a multi-organization-level approach provides more robust and comprehensive predictions of the effects of grazing on leaf traits and ecosystem functioning.

\section{Introduction}

Grazing is one of the most important drivers affecting morphology and physiology of plants and controlling structure and functioning of grassland ecosystems (Milchunas and Lauenroth, 1993; Pakeman, 2004; Cingolani et al., 2005; Semmartin et al., 2008). Plant functional traits have been considered as reflecting the adaptations to environmental variations and disturbance and trade-offs among different functions within a plant (Díaz et al., 2001; Garnier et al., 2001; Wright et al., 2004). Several studies have been conducted using functional traits to predict plant responses to grazing or the impacts of grazing on plant growth and ecosystem functioning (Díaz et al., 2001; Adler et al., 2005; Díaz et al., 2007).

Some easily measured leaf traits ("soft" traits), such as leaf size, leaf dry matter content, and specific leaf area, are found to be closely related to plant functions because they are highly correlated with "harder" traits, such as relative growth rate, photosynthetic capacity, and leaf turnover rate, and further reflect the fundamental trade-offs between growth and anti-herbivore defense (Reich et al., 1999, 2007; Wilson et al., 1999). Many studies have shown that leaf size generally

Published by Copernicus Publications on behalf of the European Geosciences Union. 
decreases under persistent grazing pressure. Because, for a given leaf area and/or mass, larger leaves provide better bites for grazer, whereas smaller leaves require more bites (Landsberg et al., 1999; Díaz et al., 2001). Therefore, grazing avoidance traits are usually associated with low palatability, such as small leaf size and high leaf dry matter content (Wardle et al., 1998; Díaz et al., 2001). In contrast, plants that tolerate grazing should have high specific leaf area and low leaf toughness, which increase shoot regrowth ability and selectivity by herbivores (Pérez-Harguindeguy et al., 2003; Cingolani et al., 2005).

Díaz et al. (2001) proposed that some easily measured plant traits, such as plant height, leaf dry mass, life history, and specific leaf area, could be used to predict plant responses to grazing. However, Vesk et al. (2004) found little evidence for predictability of grazing responses with simple traits in the semi-arid and arid shrublands and woodlands. Several studies demonstrate that plant traits response to grazing is largely mediated by resource availability (e.g., precipitation and soil nutrients) (Adler et al., 2004; Osem et al., 2004; Pakeman, 2004; Vesk et al., 2004; Anderson et al., 2007), and grazing intensity or history (Adler et al., 2004; Díaz et al., 2007; Graff et al., 2007). Also, many previous studies used leaf-level traits to predict species responses to grazing (Díaz et al., 2001; Vesk and Westoby, 2001; Adler et al., 2004), which may have potential problems in linking leaf-level trait alteration to species shift and ecosystem functioning change. This is because, at plant species level, impacts of grazing on leaf attributes depend not only on leaflevel traits but also on number of leaves per individual and number of individuals within a community. At plant functional group level, the leaf attributes may be affected by trait dissimilarity among different functional groups (complementarity hypothesis) and functional redundancy or compensation among species within the same group (Naeem, 1998; Loreau et al., 2001; Bai et al., 2004; Gamfeldt et al., 2008). Similarly, at community level, grazing impacts on leaf properties (e.g., leaf area index, leaf biomass, and specific leaf area) and ecosystem functioning are likely mediated by resource availability and niche complementarity among species with different traits (Loreau et al., 2001; Rusch et al., 2009; Schumacher and Roscher, 2009).

Several recent studies have explored grazing effects on ecosystem properties by using community-level weighted traits, calculated from leaf-level traits in combination with species abundance in a community (Garnier et al., 2007; Lavorel et al., 2008; Ansquer et al., 2009; Schumacher and Roscher, 2009). However, it is still difficult to identify the mechanisms linking grazing impact on leaf traits to ecosystem functioning based on a single organizational level analysis. Therefore, more research on "integration functions" at different organizational levels is needed, which will definitely improve our understanding on mechanistic links between plant functional traits and ecosystem properties (Violle et al., 2007).
In this study, we examined the effects of grazing on leaf traits and ecosystem functioning across six communities of three vegetation types (i.e., meadow, meadow steppe, and typical steppe) along a soil moisture gradient in the Xilin River Basin of the Inner Mongolia grassland, China. Leaf traits (i.e., leaf area, leaf dry mass and specific leaf area) of 226 species including 112 common species present at the paired ungrazed and grazed sites, standing aboveground biomass, and soil properties were systematically determined across the six grassland communities. To facilitate our analysis and interpretation, these data were organized into a nested hierarchy of four organizational levels, i.e., leaf, species, plant functional group, and community. Specifically, we try to address the following three research questions: first, how do plant leaf traits respond to grazing at different levels of organization (i.e., at the leaf, species, plant functional group and community level) and across different grassland communities in the Xilin River Basin? Second, how are the relationships between leaf traits and ecosystem functioning (e.g., standing aboveground biomass) affected by grazing and soil properties, particularly soil moisture and nutrients? Third, what are the possible mechanisms underpinning the observed responses of leaf traits to grazing?

\section{Methods}

\subsection{Study area}

This study was conducted in the Xilin River Basin $\left(43^{\circ} 26^{\prime}-\right.$ $44^{\circ} 29^{\prime} \mathrm{N}, 115^{\circ} 32^{\prime}-117^{\circ} 12^{\prime} \mathrm{E}$ ), which is located in the typical steppe region of the Inner Mongolia Plateau, northern China and covers an area of about $10000 \mathrm{~km}^{2}$, with an elevation ranging from 900 to $1500 \mathrm{~m}$ (Chen, 1988). Mean annual temperature is $0.4^{\circ} \mathrm{C}$, with the lowest mean monthly temperature $-21.4^{\circ} \mathrm{C}$ in January and the highest $19.0^{\circ} \mathrm{C}$ in July. Mean annual precipitation is $336.9 \mathrm{~mm}$, with $51-89 \%$ rainfall occurring in the growing season (May-August). The most dominant soil type is chestnut soil, while sandy soil and meadow soil are two major non-zonal soil types in this region (Chen, 1988).

Our field sampling was carried out in the areas adjacent to the Inner Mongolia Grassland Ecosystem Research Station (IMGERS), Chinese Academy of Sciences, which is located at the middle reach of the Xilin River Basin (Bai et al., 2004). We selected six paired ungrazed and grazed grassland communities of three vegetation types, including Carex appendiculata meadow, Stipa baicalensis meadow steppe, Leymus chinensis typical steppe, S. grandis typical steppe, Caragana microphylla typical steppe, and Artemisia frigida typical steppe. These communities are subjected to similar climatic conditions, such as temperature and precipitation, but differ in terms of floristic composition and soil properties, particularly soil water and nutrient content. The ungrazed sites of communities are the permanent field sites of 
Table 1. Abiotic and biotic characteristics of six grassland communities in the Xilin River Basin of Inner Mongolia, China.

\begin{tabular}{|c|c|c|c|c|c|c|c|c|c|}
\hline No. & $\begin{array}{l}\text { Community } \\
\text { type }\end{array}$ & $\begin{array}{l}\text { Vegetation } \\
\text { type }\end{array}$ & Location & $\begin{array}{l}\text { Altitude } \\
(\mathrm{m})\end{array}$ & $\begin{array}{l}\text { Soil } \\
\text { type }\end{array}$ & $\begin{array}{l}\text { Land use } \\
\text { type }\end{array}$ & $\begin{array}{l}\text { Species richness } \\
\left(\text { no. } \mathrm{m}^{-2} \text { ) }\right.\end{array}$ & $\begin{array}{l}\text { Standing aboveground } \\
\text { biomass }\left(\mathrm{g} \mathrm{m}^{-2}\right)\end{array}$ & $\begin{array}{l}\text { No. of } \\
\text { sampled } \\
\text { species }\end{array}$ \\
\hline \multirow[t]{2}{*}{1} & $\begin{array}{l}\text { Carex } \\
\text { appendiculata }\end{array}$ & Meadow & $\begin{array}{l}\text { N } 43^{\circ} 37.658^{\prime} \\
\text { E } 116^{\circ} 41.202^{\prime}\end{array}$ & 1150 & $\begin{array}{l}\text { Meadow } \\
\text { soil }\end{array}$ & $\begin{array}{l}\text { Ungrazed site } \\
\text { (fenced since 1989) }\end{array}$ & $22.6 \pm 1.9$ & $574.9 \pm 40.2$ & 98 \\
\hline & & & & & & Grazed site & $20.6 \pm 1.3$ & $382.9 \pm 61.1$ & 78 \\
\hline \multirow[t]{2}{*}{2} & $\begin{array}{l}\text { Stipa } \\
\text { baicalensis }\end{array}$ & $\begin{array}{l}\text { Meadow } \\
\text { steppe }\end{array}$ & $\begin{array}{l}\text { N } 43^{\circ} 27.248^{\prime} \\
\text { E } 116^{\circ} 47.418^{\prime}\end{array}$ & 1380 & $\begin{array}{l}\text { Dark chest- } \\
\text { nut soil }\end{array}$ & $\begin{array}{l}\text { Ungrazed site } \\
\text { (fenced since 1979) }\end{array}$ & $28.3 \pm 1.0$ & $115.8 \pm 4.4$ & 83 \\
\hline & & & & & & Grazed site & $21.5 \pm 1.8$ & $148.3 \pm 14.8$ & 63 \\
\hline \multirow[t]{2}{*}{3} & $\begin{array}{l}\text { Leymus } \\
\text { chinensis }\end{array}$ & $\begin{array}{l}\text { Typical } \\
\text { steppe }\end{array}$ & $\begin{array}{l}\mathrm{N} 43^{\circ} 32.973^{\prime} \\
\text { E } 116^{\circ} 40.715^{\prime}\end{array}$ & 1250 & $\begin{array}{l}\text { Dark chest- } \\
\text { nut soil }\end{array}$ & $\begin{array}{l}\text { Ungrazed site } \\
\text { (fenced since 1979) }\end{array}$ & $13.3 \pm 0.9$ & $178.2 \pm 10.9$ & 61 \\
\hline & & & & & & Grazed site & $9.4 \pm 0.4$ & $101.3 \pm 7.2$ & 23 \\
\hline \multirow[t]{2}{*}{4} & S. grandis & $\begin{array}{l}\text { Typical } \\
\text { steppe }\end{array}$ & $\begin{array}{l}\text { N } 43^{\circ} 32.355^{\prime} \\
\text { E } 116^{\circ} 33.198^{\prime}\end{array}$ & 1180 & $\begin{array}{l}\text { Typical } \\
\text { chestnut } \\
\text { soil }\end{array}$ & $\begin{array}{l}\text { Ungrazed site } \\
\text { (fenced since 1979) }\end{array}$ & $11.5 \pm 0.9$ & $178.0 \pm 6.9$ & 60 \\
\hline & & & & & & Grazed site & $8.1 \pm 0.5$ & $69.9 \pm 3.2$ & 26 \\
\hline \multirow[t]{2}{*}{5} & $\begin{array}{l}\text { Caragana } \\
\text { microphylla }\end{array}$ & $\begin{array}{l}\text { Typical } \\
\text { steppe }\end{array}$ & $\begin{array}{l}\text { N } 43^{\circ} 35.878^{\prime} \\
\text { E } 116^{\circ} 44.263^{\prime}\end{array}$ & 1190 & $\begin{array}{l}\text { Typical } \\
\text { chestnut } \\
\text { soil }\end{array}$ & $\begin{array}{l}\text { Ungrazed site } \\
\text { (fenced since 1983) }\end{array}$ & $11.0 \pm 1.6$ & $140.5 \pm 5.8$ & 72 \\
\hline & & & & & & (Grazed site) & $10.0+0.4$ & $59.5 \pm 4.6$ & 22 \\
\hline \multirow[t]{2}{*}{6} & $\begin{array}{l}\text { Artemisia } \\
\text { frigida }\end{array}$ & $\begin{array}{l}\text { Typical } \\
\text { steppe }\end{array}$ & $\begin{array}{l}\text { N } 43^{\circ} 37.935^{\prime} \\
\text { E } 116^{\circ} 40.598^{\prime}\end{array}$ & 1200 & $\begin{array}{l}\text { Typical } \\
\text { chestnut } \\
\text { soil }\end{array}$ & $\begin{array}{l}\text { Ungrazed site } \\
\text { (fenced since 1989) }\end{array}$ & $8.9 \pm 0.9$ & $97.1 \pm 8.1$ & 51 \\
\hline & & & & & & Grazed site & $10.4 \pm 0.5$ & $78.4 \pm 7.6$ & 48 \\
\hline
\end{tabular}

the IMGERS, which have been fenced from grazing by large animals for about 20-30 years (Table 1). The grazed sites, located outside the fence of the ungrazed sites, have been managed as free grazing pasture (mainly by sheep) since 1950s, thus they have about 60 years of grazing history. More detailed information for the six communities is shown in Table 1 .

\subsection{Vegetation and soil properties}

Vegetation measurements were conducted during 28 July to 14 August, 2007 when the standing aboveground biomass reached its annual peak, which approximated its annual net primary productivity in the ungrazed sites (Bai et al., 2004). At each site, 5-10 quadrats $(1 \times 1 \mathrm{~m}$ each) located randomly within an area of $100 \times 100 \mathrm{~m}$ were sampled, and a total of 110 quadrats were measured across the six communities. Ten quadrats were used at each site for meadow steppe and typical steppe communities, and 5 quadrats were sampled at each site for the more homogeneous meadow community. At each grazed site, these qudrads were randomly located in the areas that were not subjected to grazing during the current season.

Within each quadrat, all living biomass and current year dead materials were harvested by clipping to the soil surface, separated to species, oven dried at $70^{\circ} \mathrm{C}$ for $24 \mathrm{~h}$ to constant mass and weighed. Litter biomass within each quadrat was collected. For each species, height, number of individuals, and coverage were also measured within each quadrat at the same time. The aboveground biomass of each species was collected and transported to a laboratory for stem and leaf separation, then they were oven-dried at $70^{\circ} \mathrm{C}$ for $24 \mathrm{~h}$ to a constant mass, thus the ratio of stem to leaf (stem:leaf ratio) and plant biomass could be calculated. The total number of species and aboveground biomass collected within each quadrat were used for estimating species richness and standing aboveground biomass of community. The relative abundance of each species was obtained by calculating the proportion of the species to the total density. The relative biomass of each species was determined by its biomass ratio to the total community biomass. For each species, number of leaves per individual was determined as total leaf biomass divided by leaf dry mass. All species were further classified into plant functional groups based on life forms and water ecotypes. Four life forms are composed of perennial grasses (PG), perennial forbs (PF), annuals and biennials $(\mathrm{AB})$, and shrubs and semi-shrubs (SS). Five water ecotypes are consisted of xerophytes (X), meso-xerophytes (MX), xero-mesophytes (XM), mesophytes (M), and hygrophytes and hygro-mesophytes (HH).

After the vegetation measurements, 5 of 10 quadrats were selected randomly for soil sampling. Within each qudrat, soil samples were collected by taking three 5 -cm diameter soil cores from $0-20 \mathrm{~cm}$ depths, mixed in situ as one composite sample, hand-sorted to remove plant materials, and air dried in the lab of IMGERS. Soil samples were also taken from $0-20 \mathrm{~cm}$ layer with a soil bulk density auger, oven-dried at $105^{\circ} \mathrm{C}$ for $48 \mathrm{~h}$, and weighed to determine soil bulk density. Soil porosity was calculated as following formula: 
Soil porosity $(\%)=(1-$ soil bulk density $/ 2.65) \cdot 100 \%$

where 2.65 is the constant value of soil grain density $\left(\mathrm{g} \mathrm{cm}^{-3}\right)$.

The field holding capacity $(\%)$ of $0-20 \mathrm{~cm}$ soil layer was determined using the pressure chamber method (Page et al., 1982). Soil organic carbon was determined by the method of $\mathrm{K}_{2} \mathrm{Cr}_{2} \mathrm{O}_{7}-\mathrm{H}_{2} \mathrm{SO}_{4}$ solution digestion with the oil-bath heating. Soil total nitrogen was analyzed using a Kjeltec analyzer (Kjeltec 2300 Analyzer Unit, Sweden). Soil total phosphorus was determined using a UV/visible spectrophotometer (Beckman Coulter DU 800, USA). Soil C, N, and P contents were presented in mass basis (\%).

\subsection{Plant leaf traits}

After the vegetation and soil sampling, we randomly selected 30-50 fully grown individuals of each species and collected mature fully expanded leaves (see Cornelissen et al., 2003). All species present in the community were sampled at each site. For each species, the same number of individuals that were not subjected to grazing during the current season was also collected at the grazed sites for leaf trait measurements. In this study, 226 species from 42 families and 141 genera were collected across six ungrazed and six grazed communities in the Xilin River Basin (supplementary material S1, see http://www.biogeosciences.net/ 7/1117/2010/bg-7-1117-2010-supplement.zip). For each species, according to leaf size, about 150-600 mature and fully expanded leaves from 30-50 individuals were picked and divided into 30 samples, each with 5-20 leaves. Based on leaf morphological characters, five methods were used for leaf area measurements (supplementary material S2, see http://www.biogeosciences.net/7/1117/2010/ bg-7-1117-2010-supplement.zip). After the leaf area was measured, leaf samples were oven-dried at $65^{\circ} \mathrm{C}$ for $24 \mathrm{~h}$ to constant mass, and then specific leaf area (SLA, $\mathrm{cm}^{2} \mathrm{~g}^{-1}$ ) was calculated as the ratio of leaf area to leaf dry mass.

\subsection{Scheme for data analysis}

To facilitate the analysis and interpretation of results, we further organized leaf trait data into a nested hierarchy of four organizational levels, i.e., leaf, species, plant functional group, and community. At leaf level, we compared leaf traits of 112 species present in the paired ungrazed and grazed sites across six grassland communities based on direct measurements of leaf area, leaf dry mass, and SLA. At species level, the effects of grazing on leaf traits of dominant and common species (relative biomass $>1 \%$ ) were examined in each of the six communities. For $C$. appendiculata meadow, the subdominant species, Poa subfastigiata, which accounted for $26 \%$ of the community standing biomass, was excluded from the leaf trait analysis; because all leaves had senesced by August. Thus, a total number of 13 species was selected, which together accounted for more than $65 \%$ of the community standing biomass in both ungrazed and grazed sites. For the other five steppe communities, 7-22 dominant and common species were selected in each community, which accounted for more than $90 \%$ of the community standing biomass. The SLA, stem:leaf ratio, and standing aboveground biomass (green and current year dead) of each species were used for calculating species-level leaf area and leaf biomass for each quadrat in the paired ungrazed and grazed sites across six communities.

At plant functional group level, leaf area and leaf biomass of species that belong to a specific life form or water ecotype were summed for each quadrat in each ungrazed and grazed site, and SLA for each functional group was determined as the ratio of leaf area to leaf biomass. At community level, total leaf biomass was calculated by using plant biomass and stem:leaf ratio of each species within each quadrat at the ungarzed and grazed sites across six communities. Leaf area index (the area of leaves per soil surface area, $\mathrm{m}^{2} \mathrm{~m}^{-2}$ ) was determined by leaf biomass and specific leaf area of each species at each quadrat. The following formulae were used:

Leaf biomass $\left(\mathrm{g} \mathrm{m}^{-2}\right)=\sum_{i=1}^{n} \frac{B_{i}}{R_{i}+1}$

Leaf area index $\left(\mathrm{m}^{2} \mathrm{~m}^{-2}\right)=\sum_{i=1}^{n} B_{L i} \cdot \mathrm{SLA}_{i}$

Specific leaf area $\left(\mathrm{cm}^{2} \mathrm{~g}^{-1}\right)=\frac{\sum_{i=1}^{n} B_{L i} \cdot \mathrm{SLA}_{i}}{\sum_{i=1}^{n} \frac{B_{i}}{R_{i}+1}}$

where $B_{i}, R_{i}, B_{L i}$ and $\mathrm{SLA}_{i}$ are the aboveground biomass, stem:leaf ratio, leaf biomass, and specific leaf area of the species $i$ within each quadrat, respectively, and $n$ is the number of species in each quadrat.

\subsection{Statistical analysis}

Statistical analyses were performed using a SPSS 13.0 software (2004, SPSS Inc., USA). The effects of grazing on leaf traits for each species present at the paired ungrazed and grazed sites were tested across six grassland communities by Independent-Samples $\mathrm{T}$ test $(P<0.05)$. A total of 112 species were classified into three response groups, i.e., decreased, increased, and unchanged, based on leaf area, leaf dry mass, and SLA responses to grazing. The effects of grazing on leaf area, leaf biomass, and SLA were also examined at species, plant functional group, and community levels across six grassland communities. At plant functional group level, we examined the relationship between the leaf trait response and corresponding aboveground biomass response for each functional group across the six communities. We further explored relationships between leaf traits and soil 
properties and between leaf trait responses and soil property responses to grazing by Pearson correlation analysis.

To examine the fundamental trade-offs associated with leaf traits, we analyzed the relationship between leaf area response and leaf number response of dominant and common species for different vegetation types. The relationships between the leaf biomass and leaf area index and between standing aboveground biomass and leaf traits across six communities were also analyzed by simple linear regression. Before regression analysis, all data were transformed with the natural logarithm to improve the normality.

\section{Results}

\subsection{Variations in species leaf traits in the Xilin River Basin}

Large variations in leaf traits were observed among 226 species from six ungrazed communities in the Xilin River Basin, especially for leaf area and leaf dry mass. Leaf area varied from 0.06 to $120 \mathrm{~cm}^{2}$ [coefficient of variation $(\mathrm{CV})=181 \%$ ], with an average of $6.25 \mathrm{~cm}^{2}$; leaf dry mass varied from 0.0003 to $0.771 \mathrm{~g}(\mathrm{CV}=163 \%)$, with an average of $0.047 \mathrm{~g}$; and specific leaf area (SLA) ranged from 47 to $679 \mathrm{~cm}^{2} \mathrm{~g}^{-1}(\mathrm{CV}=46 \%)$, with an average of $141 \mathrm{~cm}^{2} \mathrm{~g}^{-1}$ (supplementary material S1, see http://www.biogeosciences. net/7/1117/2010/bg-7-1117-2010-supplement.zip). Generally, SLA showed low intra-variation but high inter-variation among life forms and water ecotypes (Fig. 1). The SLA differed significantly among four life forms $(P<0.0001)$. Annuals and biennials had much higher SLA than perennial forbs, perennial grasses, and shrubs and semi-shrubs (Fig. 1). SLA also varied substantially among five water ecotypes $(P<0.0001)$. Hygrophytes and hygro-mesophytes had much higher mean SLA than those mesophytes and xeromesophytes, with meso-xerophytes and xerophytes showing the lowest mean SLA (Fig. 1).

We further examined the responses of SLA to grazing for 112 species present at the ungrazed and grazed sites across six communities. Among four life forms, SLA for 11 of 19 annuals and biennials were increased, while 5 of 8 perennial grasses were decreased by grazing, such as L. chinensis, S. grandis and Agropyron cristatum, which are the dominant species in the typical steppe. For perennial forbs, responses of SLA were relatively balanced among the three groups, 28 of 81 species increased, 25 species decreased, and 28 species remained unchanged. Among water ecotypes, for hygrophytes and hygro-mesophytes, SLA in 3 of 8 species increased and 5 species remained unchanged. SLA for most of mesophytes and xero-mesophytes was either increased (27) or remained unchanged (18). For xerophytes and meso-xerophytes, 23 of 50 species were diminished, 16 species were enhanced, and 11 species remained unchanged.

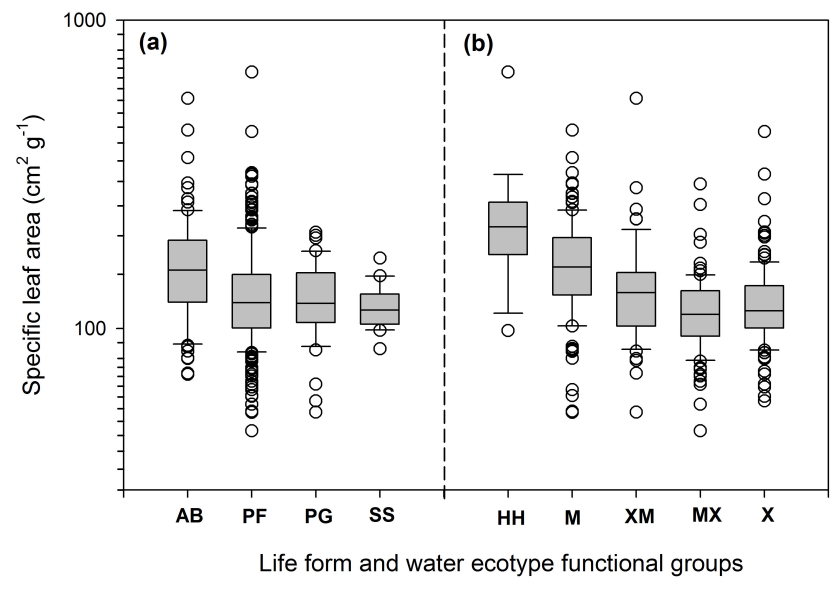

Fig. 1. Box plots of specific leaf area (SLA) for different life forms (a) and water ecotypes (b) in the Xilin River Basin, Inner Mongolia, China. The values of SLA were $\log _{10}$-transformed before analysis. Box plots show the interquartile range and median (central line); whiskers indicate the 10th and 90th percentiles. No whiskers are shown for groups with $<10$ species. Abbreviations for life forms: AB, Annuals and biennials; PF, Perennial forbs; PG, Perennial grasses; SS, Shrubs and semi-shrubs. Abbreviations for water ecotypes: X, Xerophytes; MX, Meso-xerophytes; XM, Xeromesophytes; M, Mesophytes; and HH, Hygrophytes and hygromesophytes.

\subsection{Leaf level trait responses to grazing}

Among three vegetation types examined, there were 45 shared species at the ungrazed and grazed sites in $C$. appendiculata meadow, 55 shared species in S. baicalensis meadow steppe, and 88 shared species in the typical steppe (i.e., L. chinensis, S. grandis, C. microphylla, and A. frigid communities). On average, leaf area and leaf dry mass for $56 \%$ of the species present in the six communities were significantly decreased by grazing $(P<0.05)$, with $24 \%$ of the species exhibiting an significant increase $(P<0.05)$ and the other $20 \%$ species showing no change in both leaf area and leaf dry mass (Fig. 2). Among the six communities, leaf area and leaf dry mass for $57-86 \%$ of species in the typical steppe and $62-85 \%$ of species in the meadow were diminished by grazing (Fig. 2). In the meadow steppe, however, changes in leaf area and dry mass were relatively balanced among three distinct response groups; leaf area and dry mass in $26 \%$ of species decreased, both increased in $36 \%$ of species, and both remained unchanged in $24 \%$ of species (Fig. 2).

On average, SLA also showed a relatively balanced proportion of response among the three groups across six communities; that is, grazing increased SLA in 37\% of the common species, decreased it in $35 \%$, and had no effect on it in $28 \%$ of the species (Fig. 2). In C. appendiculata meadow, the SLA for $51 \%$ of the species was increased by grazing. In the typical steppe communities, however, the SLA for 50\% of the species was decreased by grazing (Fig. 2). Again, the 


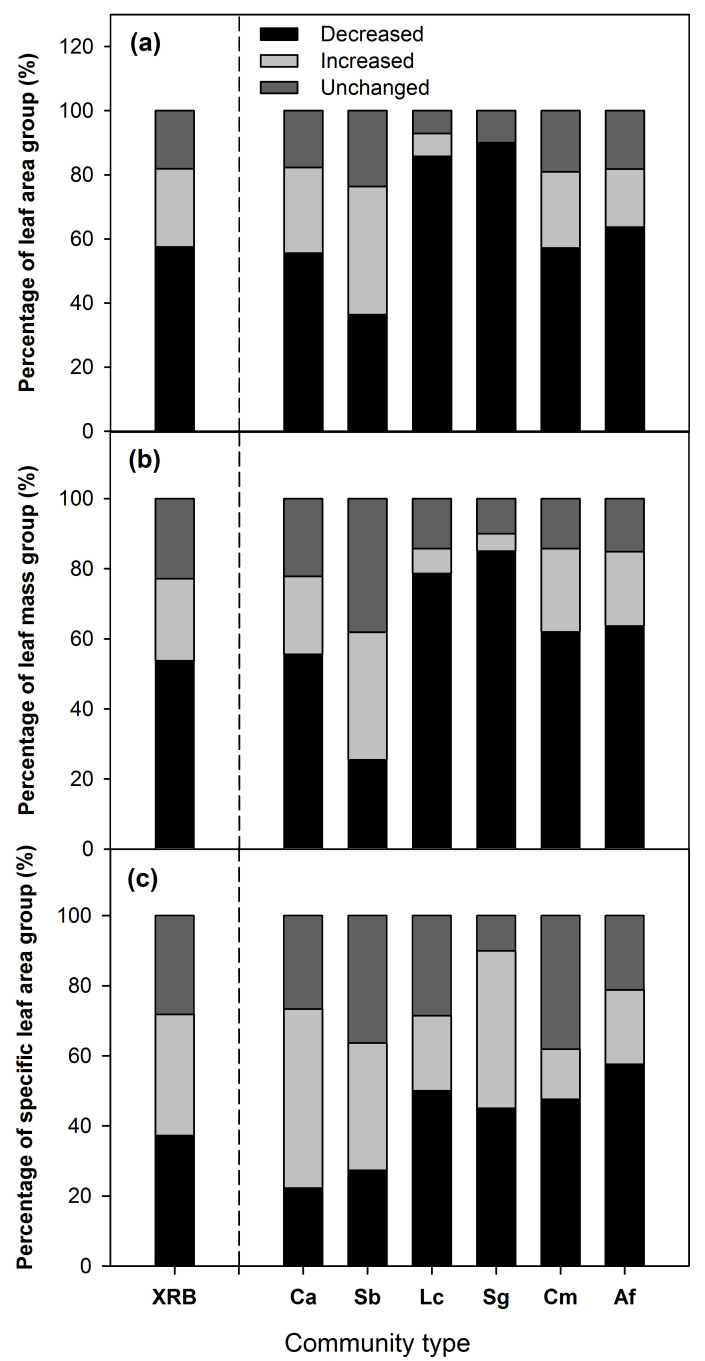

Fig. 2. Percentages of species categorized as three groups based on responses of leaf area (a), leaf mass (b), and specific leaf area (c) to grazing in six grassland communities. Abbreviations: Ca, Carex appendiculata meadow; Sb, Stipa baicalensis meadow steppe; Lc, Leymus chinensis typical steppe; Sg, Stipa grandis typical steppe; $\mathrm{Cm}$, Caragana microphylla typical steppe; Af, Artemisia frigida typical steppe. XRB denotes the percentage of species averaged over the six communities in the Xilin River Basin.

proportions of the three response groups were almost balanced in the $S$. baicalensis meadow steppe, with $36 \%$ of the species illustrating increased SLA, $36 \%$ of the species showing unchanged SLA, and the other $27 \%$ of the species exhibiting decreased SLA (Fig. 2). On the whole, grazing had more negative effects on leaf area and dry mass than SLA at the leaf level, and it had more negative effects on species leaf traits in typical steppe than in meadow and meadow steppe.

\subsection{Species level leaf trait responses}

In the $C$. appendiculata meadow, leaf area and leaf biomass for 1 of 13 species were significantly increased by grazing, with other 12 species being unchanged (Fig. 3). In the $S$. baicalensis meadow steppe, leaf area and leaf biomass for 5 of 22 species were significantly diminished by grazing, and both remained unchanged for the other 17 species (Fig. 3). As compared with the meadow and meadow steppe communities, the negative effects of grazing on leaf area and leaf biomass of dominant and common species were greatest and most consistent in the typical steppe communities, i.e., 5 of 12 species for L. chinensis community, 5 of 7 species for $S$. grandis community, 5 of 8 species for $C$. microphylla community, and 3 of 7 species for A. frigid community (Fig. 3).

For different vegetation types, we further examined the relationship between leaf area response and leaf number response. The results showed that leaf area response was negatively correlated with leaf number response $(P=0.006)$, when all 69 common species present at both grazed and ungrazed sites in six communities were pooled together (Fig. 4). In the C. appendiculata meadow, leaf area response was negatively correlated with leaf area response among 8 common species occurred at both grazed and ungrazed sites $(P=0.018)$ (Fig. 4). In $S$. baicalensis meadow steppe, a significantly negative relationship was also found between the leaf area response and leaf number response among 22 shared species $(P=0.035$, Fig. 4$)$. There was no significant relationship between leaf area response and leaf number response among 34 species present at both ungrazed and grazed sites across the four typical steppe communities $(P=0.065)$. However, when the species were divided into two groups based on leaf area and leaf biomass responses to grazing (i.e., both increased or decreased and both unchanged), leaf number response was still negatively correlated with leaf area response $(P=0.038)$ among 14 species, for which both leaf area and leaf biomass were not affected by grazing (Fig. 4).

\subsection{Plant functional group level leaf trait responses}

At plant functional group level, responses of SLA, leaf area, and leaf biomass were relatively consistent in typical steppe communities than meadow and meadow steppe communities, and the magnitude of these changes were generally greater for perennial grasses and perennial forbs than the other two life forms (Fig. 5). In the C. appendiculata meadow, SLA for three available life forms remained unchanged, while grazing diminished leaf area and leaf biomass of perennial grasses and had no effect on both leaf area and leaf biomass of the other life forms (Fig. 5). In S. baicalensis meadow steppe, SLA of perennial grasses and perennial forbs was significantly decreased while SLA of annuals and biennials and shrubs and semi-shrubs remained unchanged, though leaf area and leaf biomass of four life forms were generally 

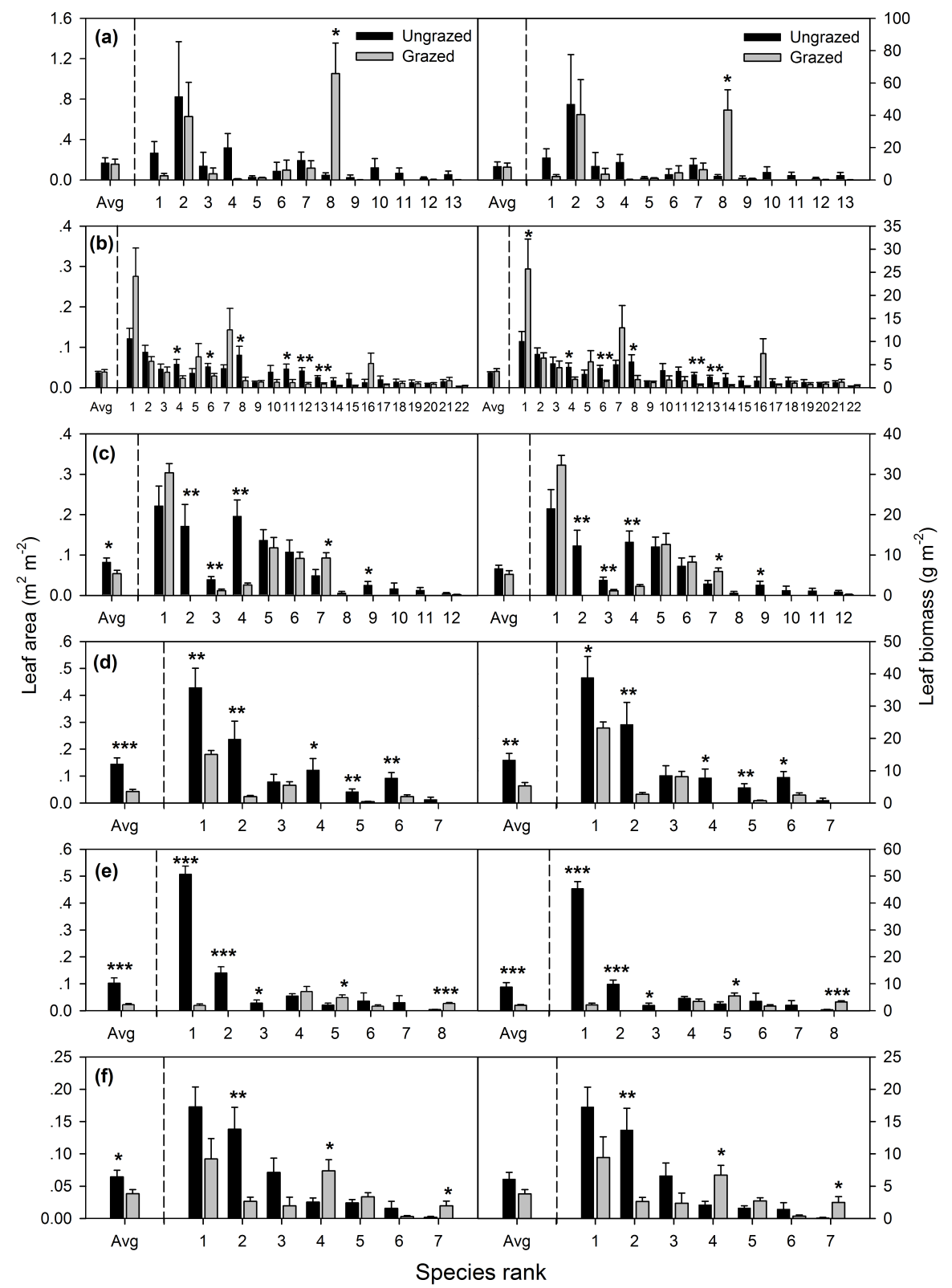

Fig. 3. Effects of grazing on leaf area and leaf biomass of dominant and common species in the six communities. (a) C. appendiculata meadow; (b) S. baicalensis meadow steppe, (c) L. chinensis typical steppe; (d) S. grandis typical steppe; (e) C. microphylla typical steppe; (f) A. frigida typical steppe. The species were ranked based on their relative biomass. Avg denotes the average leaf trait value of dominant and common species in each community. * **, and *** denote significant difference at $P<0.05, P<0.01$, and $P<0.001$, respectively. Columns without asterisk denotations indicated that there was no significant difference between the ungrazed and grazed sites. The error bars are mean+SE.

unaffected by grazing (Fig. 5). In the typical steppe, SLA for three of four life forms except shrubs and semi-shrubs was mostly reduced by grazing, although responses of leaf area and leaf biomass were inconsistent across different life forms and communities (Fig. 5). Specifically, leaf area and leaf biomass of perennial grasses were significantly reduced by grazing in two communities ( $S$. grandis and $C$. microphylla), but both were not affected in the other two communities, i.e., L. chinensis and A. frigida (Fig. 5). Both leaf area and leaf biomass of perennial forbs in three of four communities (except $L$. chinensis community) were decreased by grazing. For annuals and biennials and shrubs and semi-shrubs, leaf area and leaf biomass remained unchanged, except for the annuals and biennials in the $S$. grandis community and the shrubs and semi-shrubs in L. chinensis community in which leaf area and leaf biomass were diminished by gazing (Fig. 5). 

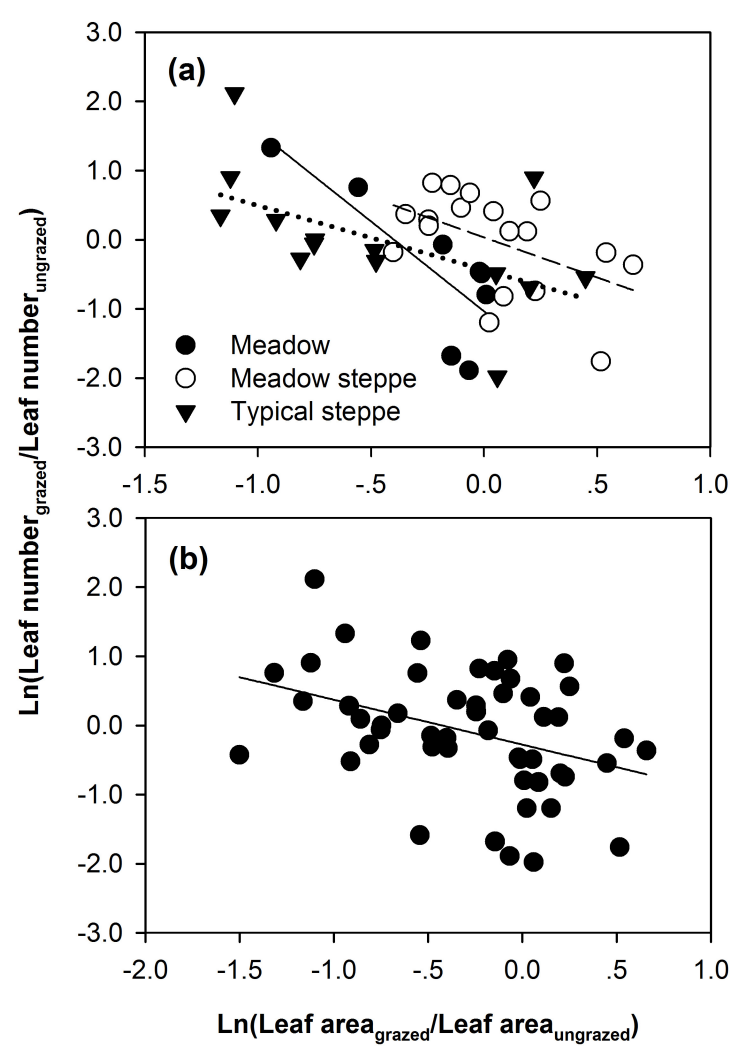

Fig. 4. The relationships between responses of leaf area and leaf number per individual for dominant and common species within each vegetation type (a) and over all vegetation types (b). Data were transformed with the natural logarithm before regression analysis to improve the normality.

Similarly, response patterns of SLA, leaf area, and leaf biomass were generally more consistent in the typical steppe than the meadow and meadow steppe, and the grazing impacts were greater in magnitude on xerophytes and mesoxerophytes than others among five water ecotypes (Fig. 6). In the $C$. appendiculata meadow, leaf area, leaf biomass, and SLA of five water ecotypes remained largely unchanged (Fig. 6). In the S. baicalensis meadow steppe, grazing significantly reduced SLA of meso-xerophytes, xero-mesophytes, and mesophytes, enhanced leaf area and leaf biomass of xerophytes, diminished leaf area and leaf biomass of mesoxerophytes, had no effects on xero-mesophytes, and decreased leaf area of mesophytes (Fig. 6). Across four typical steppe communities, leaf area, leaf biomass, and SLA of xerophytes and meso-xerophytes were mostly diminished by grazing; while those of the xero-mesophytes and mesophytes were largely unaffected, except for $S$. grandis community in which leaf area, leaf biomass, and SLA of xero-mesophytes were all reduced by grazing (Fig. 6). SLA of mesophytes in $L$. chinensis and $S$. grandis communities was also significantly decreased by grazing (Fig. 6).
Our results also showed that there were statistically significant positive relationships between the leaf area responses and aboveground biomass responses for all life forms (e.g., perennial grasses, perennial forbs, annuals and biennials, and shrub and semi-shrubs) and water ecotypes (e.g., xerophytes, meso-xerophytes, xero-mesophytes, and mesophytes) across the six grassland communities $(P<0.05$; Fig. 7). Our results further revealed that the positive effect of grazing on leaf traits was found only for perennial grasses and shrub and semi-shrubs in the meadow steppe, and perennial forbs in the meadow (Fig. 7). Among the water ecotypes, the positive effect of grazing on leaf traits was found only for xeromesophytes in the typical steppe, with others showing the negative impacts (Fig. 7).

\subsection{Community level leaf trait responses}

At community level, we found that leaf area index, leaf biomass, and SLA were generally unaffected by grazing across meadow and meadow steppe communities, except for the SLA of S. baicalensis community (Fig. 8). In contrast, leaf area index, leaf biomass, and SLA were all significantly reduced by grazing across four typical steppe communities (Fig. 8). The magnitude of these changes was greater in leaf area index and leaf biomass than SLA, and the impacts were larger in L. chinensis, S. grandis, and C. microphylla communities than A. frigida community. When averaged over the four typical steppe communities, the leaf area index in the grazed sites decreased by $57 \%$, leaf biomass decreased by $48 \%$, and SLA decreased by $16 \%$, compared to those in the ungrazed sites.

\subsection{Relationships between plant community and soil properties}

At the community level, leaf area index was positively correlated with leaf biomass across all ungrazed $(P=0.0021)$ and grazed $(P=0.0002)$ communities in the Xilin River Basin (Fig. 9). Moreover, standing aboveground biomass was positively correlated with leaf area index (for ungrazed sites, $P=$ 0.0020 ; for grazed sites, $P<0.0001$ ) and SLA (for ungrazed sites, $P=0.0047$; for grazed sites, $P=0.0113$ ). For the ungrazed communities, the leaf area index, leaf biomass, SLA, and standing aboveground biomass were all positively correlated with field holding capacity, soil porosity, soil organic carbon, soil total nitrogen and phosphorus, but negatively correlated with soil bulk density (Table 2). However, we found that all soil properties examined were not significantly affected by grazing across six communities $(P>0.05)$, and the responses of plant community properties were also not significantly correlated to those of soil properties (Table 2). 

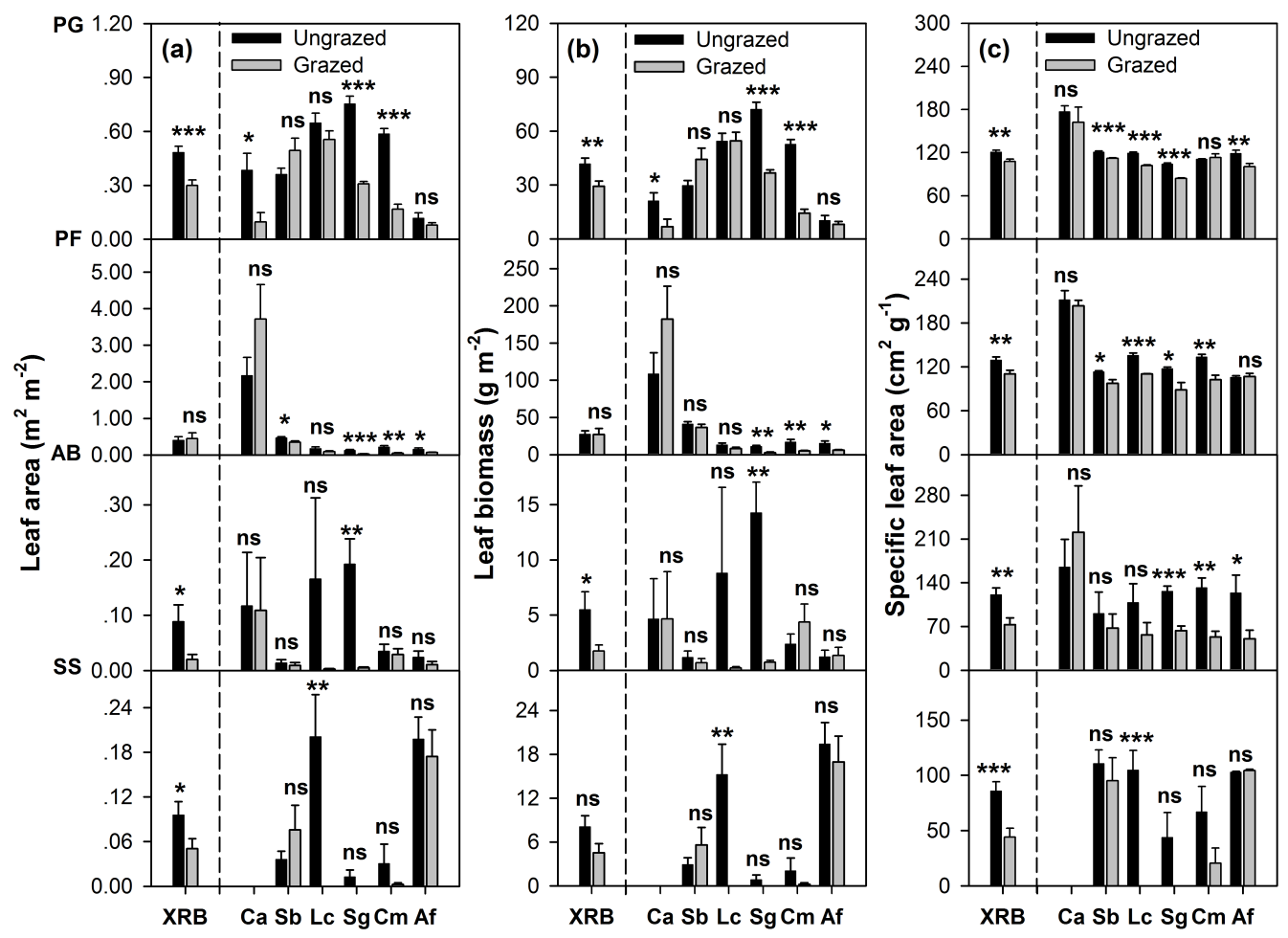

Community type

Fig. 5. Effects of grazing on leaf area (a), leaf biomass (b), and specific leaf area (c) of four life forms in the six communities. PG=Perennial grasses; $\mathrm{PF}=$ Perennial forbs; $\mathrm{AB}=$ Annuals and biennials; $\mathrm{SS}=$ Shrubs and semi-shrubs. All symbols are derived as from Fig. 2 and Fig. 3.

Table 2. Relationships between plant community and soil properties across the six ungrazed and grazed communities.

\begin{tabular}{|c|c|c|c|c|c|c|}
\hline $\begin{array}{l}\text { Community } \\
\text { properties }\end{array}$ & $\begin{array}{l}\text { Field holding } \\
\text { capacity }(\%)\end{array}$ & $\begin{array}{l}\text { Soil bulk } \\
\text { density }\left(\mathrm{g} \mathrm{cm}^{-3}\right)\end{array}$ & $\begin{array}{l}\text { Soil porosity } \\
(\%)\end{array}$ & $\begin{array}{l}\text { Soil organic } \\
\text { carbon }(\%)\end{array}$ & $\begin{array}{l}\text { Soil total } \\
\text { nitrogen }(\%)\end{array}$ & $\begin{array}{l}\text { Soil total } \\
\text { phosphorus (\%) }\end{array}$ \\
\hline \multicolumn{7}{|c|}{ Ungrazed sites $(n=6)$} \\
\hline $\begin{array}{l}\text { Leaf area index } \\
\left(\mathrm{m}^{2} \mathrm{~m}^{-2}\right)\end{array}$ & $0.937 * *$ & $-0.891 *$ & $0.886^{*}$ & $0.978 * *$ & $0.980 * *$ & $0.948 * *$ \\
\hline $\begin{array}{l}\text { Leaf biomass } \\
\left(\mathrm{g} \mathrm{m}^{-2}\right)\end{array}$ & $0.874 *$ & $-0.826^{*}$ & $0.820 *$ & $0.864 *$ & $0.892 *$ & $0.922 * *$ \\
\hline $\begin{array}{l}\text { Specific leaf } \\
\text { area }\left(\mathrm{cm}^{2} \mathrm{~g}^{-1}\right)\end{array}$ & $0.907 *$ & $-0.852 *$ & $0.848^{*}$ & $0.985^{* * *}$ & $0.975 * *$ & $0.925 * *$ \\
\hline $\begin{array}{l}\text { Standing } \\
\text { aboveground } \\
\text { biomass }\left(\mathrm{g} \mathrm{m}^{-2}\right)\end{array}$ & $0.916^{*}$ & $-0.876^{*}$ & $0.872 *$ & $0.982 * * *$ & $0.967 * *$ & $0.897 *$ \\
\hline \multicolumn{7}{|c|}{ Grazed sites $(n=6)$} \\
\hline Leaf area index & 0.321 & 0.248 & -0.142 & -0.565 & -0.611 & -0.592 \\
\hline Leaf biomass & 0.426 & 0.229 & -0.108 & -0.561 & -0.609 & -0.591 \\
\hline Specific leaf area & -0.342 & 0.423 & -0.360 & -0.593 & -0.617 & -0.584 \\
\hline $\begin{array}{l}\text { Standing } \\
\text { aboveground } \\
\text { biomass }\end{array}$ & 0.129 & -0.120 & 0.011 & -0.025 & -0.056 & -0.073 \\
\hline
\end{tabular}

The responses of plant community and soil properties to grazing were transformed with the natural logarithm before regression analysis to improve the normality. * **, and $* * *$ denote the correlation coefficients are significant at $P<0.05, P<0.01$, and $P<0.001$ (2-tailed), respectively. $n=$ number of communities. 

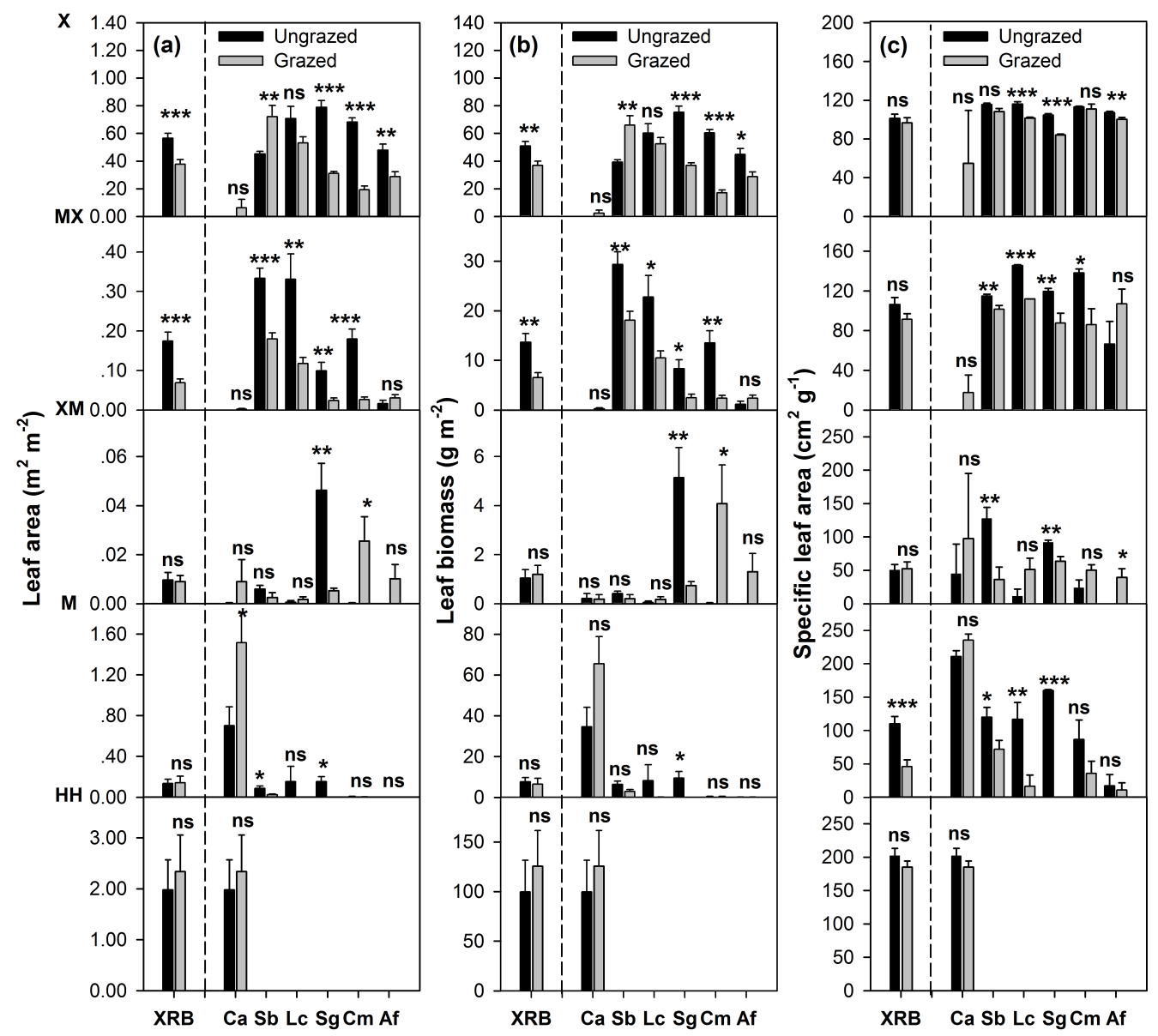

Community type

Fig. 6. Effects of grazing on leaf area (a), leaf biomass (b), and specific leaf area (c) of five water ecotypes in the six communities. $\mathrm{X}=$ Xerophytes; MX=Meso-xerophytes; XM=Xero-mesophytes; M=Mesophytes; HH=Hygrophytes and hygro-mesophytes. All symbols are derived as Figs. 2 and 3.

\section{Discussion}

\subsection{Patterns of leaf trait responses to grazing at different organizational levels}

To our knowledge, our study represents the first systematic examination of the effects of grazing on leaf traits and ecosystem functioning using a multi-organization-level approach across a broad range of plant communities and vegetation types in the Inner Mongolia grassland. Our findings demonstrate that the effects of grazing on leaf area, leaf dry mass/biomass, and SLA differed substantially when scaling up from leaf-level to species, functional group (e.g., life forms and water ecotype types), and community levels. In the $C$. appendiculata meadow, for instance, leaf area, leaf dry mass, and SLA for more than $78 \%$ of species were either significantly decreased or increased by grazing at the leaf level. At the species level, however, leaf area and leaf biomass were significantly affected (either increased or decreased) by grazing for only $8 \%$ of the common species, with no dominant species being affected. At the plant functional group level, the leaf area, leaf biomass, and SLA were generally unaffected by grazing for most of the life forms and water ecotypes. At the community level, the leaf area index, leaf biomass, and SLA remained consistently unchanged. This indicates that, in the meadow, the effects of grazing on leaf traits diminished progressively along the hierarchy of organizational levels.

In the typical steppe communities, however, the effects of grazing on leaf traits were predominantly negative and the magnitude of these effects increased considerably at higher organizational levels. At the leaf level, leaf area, leaf dry mass, and SLA for more than $65 \%$ of species were decreased and only $17 \%$ of species were increased by grazing. At the species level, leaf area and leaf biomass for $38 \%$ of the species, mostly the dominant species, were decreased, and 


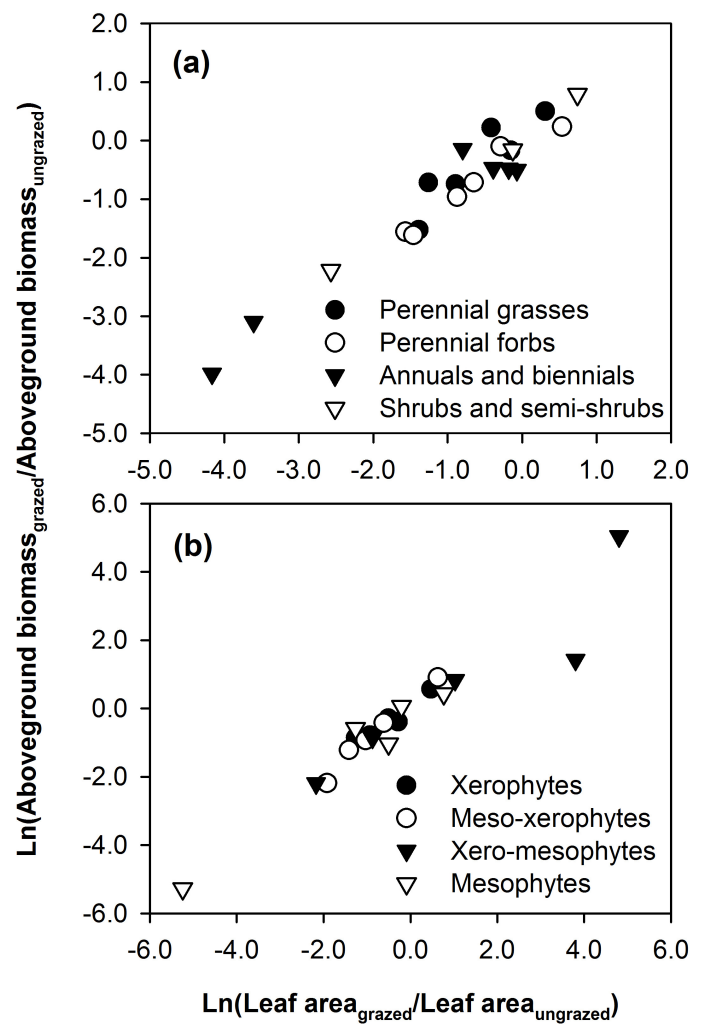

Fig. 7. The relationships between responses of the leaf area and aboveground biomass for different life forms (a), and water ecotypes (b) across the six communities. Data were transformed with the natural logarithm before regression analysis to improve the normality.

$15 \%$ of the species increased by grazing. At the functional group level, the leaf area, leaf biomass, and SLA of the dominant life forms (e.g., perennial grasses and perennial forbs) and water ecotypes (e.g., xerophytes and meso-xerophytes) were decreased by grazing. At the community level, the leaf area index, leaf biomass, and SLA were all reduced substantially by grazing. For $S$. baicalensis meadow steppe, the response patterns were largely between the meadow and typical steppe communities across different organizational levels.

These results clearly exhibit that the effects of grazing on leaf traits are scale dependant and they may change with vegetation type or site conditions. This suggests that the multiorganization-level approach used here provides more robust and comprehensive predictions on the effects of grazing on leaf traits and ecosystem functioning than previous investigations using only one level of organization. Recent studies on plant functional trait have been focused mostly on leaflevel traits (Díaz et al., 2001; Vesk and Westoby, 2001; Adler et al., 2004) or community-level weighted traits (Cingolani et al., 2005; Quested et al., 2007; Schumacher and Roscher, 2009) to explore the effects of grazing on plant morpholog-

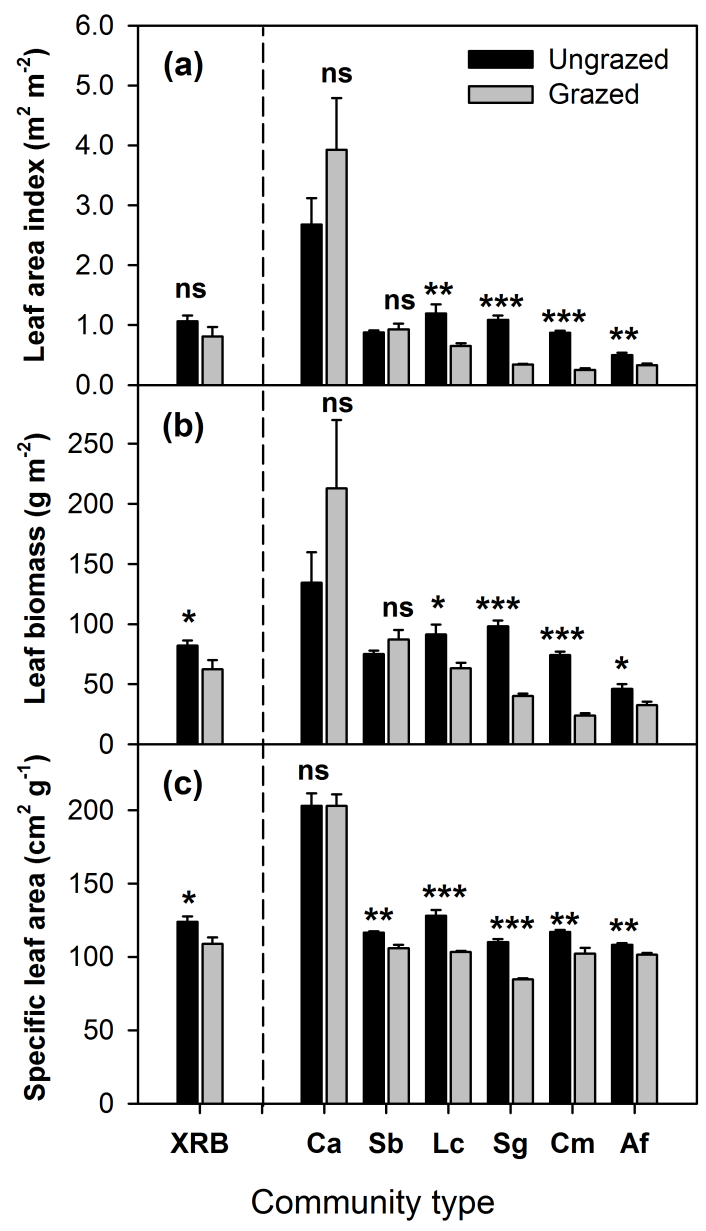

Fig. 8. Effects of grazing on leaf area index (a), leaf biomass (b), and specific leaf area (c) at the community level. All symbols are derived as from Fig. 2 and Fig. 3.

ical and physiological attributes and ecosystem functioning. Our study, however, provides some new insights into the trait responses to grazing and linkages between changes in leaf traits and ecosystem functioning at different levels of organization. Our general conclusions are also corroborated by several recent studies, which proposed that aggregated trait improved predictive power of ecosystem function (Cingolani et al., 2005; Quested et al., 2007; Schumacher and Roscher, 2009) compared to the low predictability of simple traits (Vesk et al., 2004).

\subsection{Mechanisms underpinning leaf trait responses to grazing}

Several mechanisms are likely to be responsible for the observed responses of leaf traits to grazing at different levels of organization and among vegetation types. First, soil properties, particularly soil water and nutrient availability, are two major factors driving the differential responses of leaf traits to grazing between the meadow and typical steppe 

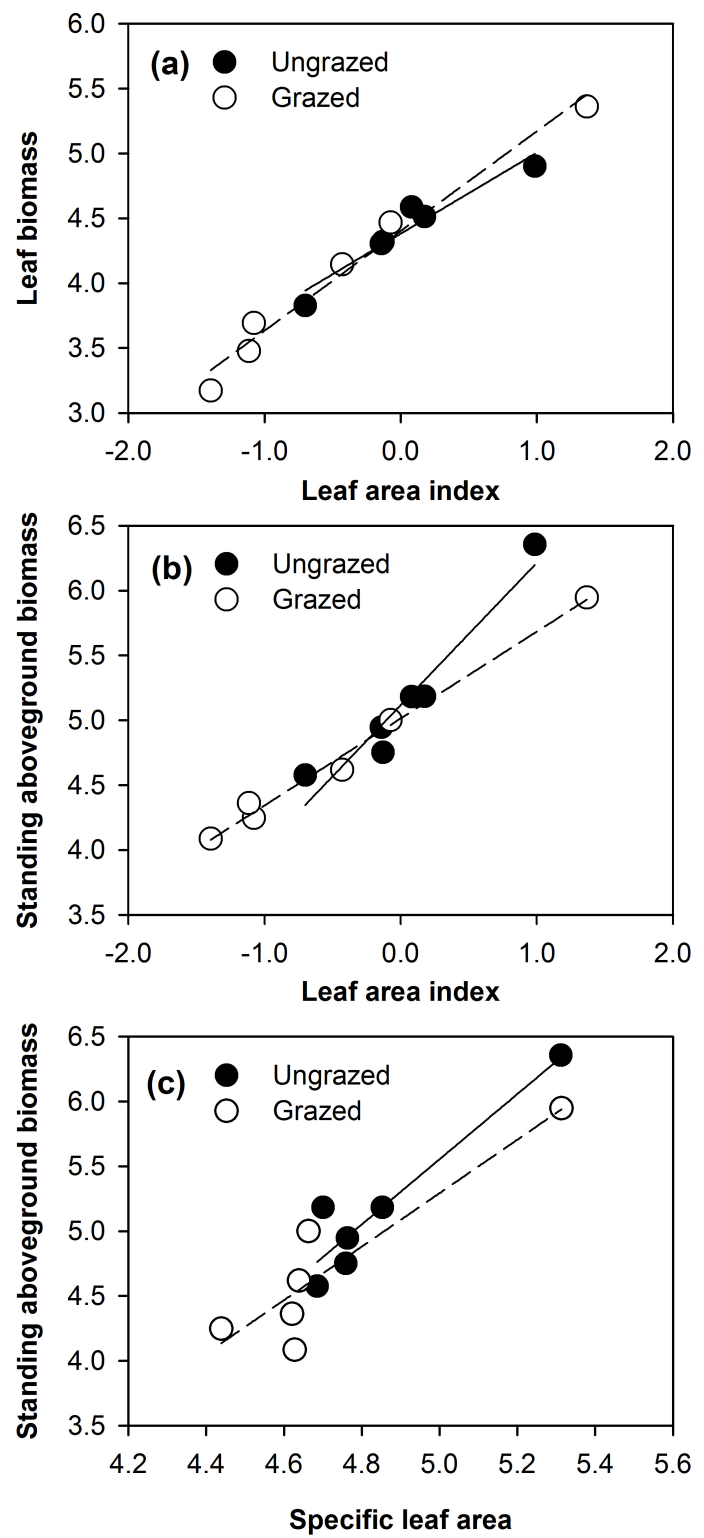

Fig. 9. The relationships between community-level leaf attributes and standing aboveground biomass across the six ungrazed and grazed communities. Data were transformed with the natural logarithm before regression analysis to improve the normality.

communities. Water is a key factor limiting plant growth, species richness, productivity, and stability of grassland ecosystems (Sala et al., 1988; Knapp et al., 2001; Bai et al., 2004, 2007, 2008). Our results revealed that growth responses following grazing were mediated by site conditions, with slight positive responses in wetter sites, and negative responses in drier sites. These findings are corroborated by a previous study in the same area where the grazing impacts on plant morphological traits (e.g., height, canopy size, and individual biomass) and stem-leaf biomass allocation were strongly mediated by soil moisture, with species in the wet meadow being less affected than in dry typical steppe (Ren et al., 2009). Another recent study of ours also suggested that high annual precipitation could substantially ameliorate the negative effects of grazing on functional traits (i.e., leaf area, leaf dry mass and net photosynthetic rate) of L. chinensis, a dominant species in typical steppe (Zheng et al., 2010). In addition, we found that soil properties, including field holding capacity, soil organic carbon, soil total nitrogen and phosphorus contents, which were greatest in the meadow but lowest in the typical steppe, may also be attributable to the distinct responses of leaf traits between the two vegetation types; because soil properties, particularly soil moisture and nitrogen, are tightly coupled in these ecosystems (Bai et al., 2008, 2010). These findings are also consistent with previous studies (Adler et al., 2004; Osem et al., 2004; Pakeman, 2004; Vesk et al., 2004; Schumacher and Roscher, 2009).

Second, the observed responses of leaf traits to grazing at different levels of organization are largely governed by functional trade-offs between plant traits. We hypothesized that trade-offs between leaf size and number of leaves per individual (Kleiman and Aarssen, 2007) and between plant size and density (Aarssen et al., 2006) could diminish the negative effects of grazing when scaling up from leaf-level to species, functional group, and community levels. Our hypothesis is partly supported by the negative relationship between the leaf area response and leaf number response for dominant and common species across three vegetation types and within the meadow and meadow steppe. In the typical steppe, the leaf size vs. number trade-off was only found among $47 \%$ of the common species. This is likely to be a potential mechanism that species adopt increasing leaf number to compensate for leaf area loss as leaf size reduces under the frequent grazing disturbance. However, the trade-off between plant size and density was not observed in this study. In addition, we recently revealed that $L$. chinensis adopted the high regrowth rate to compensate for the biomass loss by frequent grazing in the wet year, while adopted the low growth rate for more conservative resource use in the dry year (Zheng et al., 2010). Our findings generally support the notion that functional trade-offs among plant traits within a species may promote its survivorship with fluctuating environments (Grime, 2001; Westoby et al., 2002; Reich et al., 2007; Ordonez et al., 2009).

Third, the differentiation in avoidance (escape from grazers) and tolerance (regrowth capacity after defoliation) strategies among coexisting species is likely to be responsible for the different responses among life forms and water ecotypes. In this study, both similar and different strategies were found among life forms and water ecotypes in terms of leaf-level trait responses to grazing. Leaf area and leaf dry mass of most species were decreased by grazing, indicating that they adopted an avoidance strategy to decrease the palatability and selectivity by herbivores (Díaz et al., 2001; Klimesova et al., 2008; Rusch et al., 2009). Specific leaf area, the ratio of leaf area to leaf dry mass, is relatively stable and closely related 
to photosynthetic physiology and relative growth rate, thus it could better reflect plant strategies (Shipley, 1995). Among four life forms, we found that SLA of most perennial grasses was decreased, which might be responsible for the decreased leaf area and leaf biomass at functional group and community levels in the typical steppe dominated by perennial grasses. However, SLA of most annuals and biennials was increased by grazing, suggesting that annuals and biennials adopt high SLA as a grazing tolerant trait. This might be the reason that leaf area and leaf biomass of annuals and biennials were less affected by grazing at the functional group level. Our findings support the point of view that annuals and biennials, being short-lived and mostly opportunists with high relative growth rate, are more tolerant to herbivory (Vesk et al., 2004). SLA of perennial forbs, in contrast, showed a divergent response to grazing. This is likely to be responsible for the least impact of grazing on leaf traits at both functional group and community levels in the meadow, in which more than $60 \%$ of species and $80 \%$ of the total leaf biomass were composed of perennial forbs.

It has been proposed that species with longer leaf life-span generally have lower SLA, but greater investment in structural defense (Warren and Adams, 2000). In our study, leaf life-span, indicated by SLA, increased from annuals and biennials to perennial forbs, perennial grasses, and shrubs and semi-shrubs, implying annuals and biennials are more tolerant whereas shrubs and semi-shrubs are more resistant to grazing. This supports the hypothesis that there exists a fundamental trade-off between leaf productivity and persistence (Warren and Adams, 2000; Zheng and Shangguan, 2007; He et al., 2009). Our findings also showed that leaf area and leaf biomass of xerophytes and meso-xerophytes, two dominant water ecotypes in the meadow steppe and typical steppe, were greatly decreased by grazing. However, grazing had less impact on leaf area and leaf biomass of hygrophytes, hygro-mesophytes, and mesophytes, which dominate in the meadow. SLA of most xerophytes and meso-xerophytes were decreased by grazing, while SLA of mesophytes and hygrophytes were mostly increased or unchanged, indicating that species in the wet habitats are generally more tolerant to grazing. Our findings are corroborated by previous studies that aridity appeared to favor grazing-avoidance traits, while grazing-tolerance traits increased with water availability (Adler et al., 2004; Cingolani et al., 2005).

\subsection{Linkage between changes in leaf traits and ecosystem functioning}

Leaves, as important assimilation organs, are sensitive to environmental variables, i.e. $\mathrm{CO}_{2}$ concentration, precipitation, temperature, and light (Mott et al., 1982), and humman disturbance, such as grazing, clipping, and defoliation (Holechek et al., 2002). Our findings demonstrated that, for all life form and water ecotype functional groups, the leaf area responses to grazing were positively correlated with aboveground biomass responses across the six communities. At community level, leaf area index, leaf biomass and SLA were all positively correlated with standing aboveground biomass across the ungrazed and grazed communities. This indicates that grazing induced changes in leaf area index, leaf biomass and SLA will definitely affect ecosystem functioning, particularly, annual net primary productivity. Indeed, our study suggested that leaf area index, leaf biomass and SLA in the typical steppe were all reduced by grazing, and consequently standing aboveground biomass was decreased by $48 \%$ on average across the four communities. For the meadow and meadow steppe, leaf area index, leaf biomass, SLA, and standing aboveground biomass mostly remained unchanged.

Among four typical steppe communities, grazing-induced decrease in total biomass production is closely related to changes in leaf traits across different levels of organization. Our results demonstrate that the magnitude of grazing impacts on leaf traits increased at higher levels, suggesting that the drivers may also change across the nested hierarchy of organizational levels. At leaf level, the response patterns of leaf traits to grazing are mainly governed by the direct effects of grazing and site conditions. At species level, the leaf traits responses are mediated primarily by the number of leaves per individual, density of each species, and their interactions with the direct effects of grazing on leaf-level traits. Our analysis indicates that the density of $35 \%$ of the dominant and subdominant species was decreased by grazing. At functional group and community levels, the grazing impacts on leaf attributes are caused mainly by changes in dominant species and functional groups. For example, the negative effects of grazing on leaf traits mostly occurred among dominant life forms (e.g., perennial grasses and perennial forbs) and water ecotypes (e.g., xerophytes and meso-xerophytes). Moreover, long-term overgrazing has led to shifts in dominant species, particularly in the typical steppe, the original dominant species $L$. chinensis and $S$. grandis were replaced by drought and grazing resistant species A. cristatum, $C$. squarrosa, and A. frigida. Our major findings are corroborated by previous studies in the same region $(\mathrm{Li}, 1988$; Bai et al., 2002; Auerswald et al., 2009) and beyond the Inner Mongolia grassland (Anderson and Briske, 1995; McIntyre and Lavorel, 2001; Pakeman, 2004; Semmartin et al., 2004; Díaz et al., 2007).

Our findings suggest that, compared to the remarkable changes in leaf traits and standing aboveground biomass, the soil properties were generally less unaffected by grazing. Our study further illustrates that there were no significant relationships between the plant community responses and soil property responses, indicating that effects of grazing on soil properties may be subject to a time-lag compared with the strong responses of plant traits and community attributes, which is consistent with the general findings from a metaanalysis based on a worldwide 236-site data (Milchunas and Lauenroth, 1993). 


\section{Conclusions}

Current studies, which focused mostly on leaf-level traits or community-level weighted traits, have difficulties in identifying the mechanisms linking grazing impact on leaf traits to ecosystem functioning. Using a multi-organization-level approach, our study demonstrates that the effects of grazing on leaf traits are scale dependant and they may change with vegetation type or site conditions. Our analysis indicates that the observed response patterns are largely driven by three mechanisms, i.e., differences in soil water and nutrient availability among vegetation types, functional trade-offs between leaf size and number of leaves per individual, and differentiation in avoidance and tolerance strategies among coexisting species. At both the functional group and community levels, standing aboveground biomass increased with leaf area and specific leaf area. Compared with the large changes in leaf traits and standing aboveground biomass, the soil properties were generally unaffected by grazing. Our findings demonstrate that the multi-organization-level approach used here seems to provide more robust and comprehensive predictions on the effects of grazing on leaf traits and ecosystem functioning.

Acknowledgements. We thank Q. M. Pan, J. H. Huang, Q. B. Wang, X. G. Han and two anonymous reviewers for their helpful comments on the early version of this manuscript. This research was supported by State Key Basic Research and Development Program of China (2009CB421102 and 2007CB106801) and the National Natural Science Foundation of China (30825008 and 30900193).

Edited by: F. Carswell

\section{References}

Aarssen, L. W., Schamp, B. S., and Pither, J.: Why are there so many small plants? Implications for species coexistence, J. Ecol., 94, 569-580, 2006.

Adler, P. B., Milchunas, D. G., Lauenroth, W. K., Sala, O. E., and Burke, I. C.: Functional traits of graminoids in semi-arid steppes: a test of grazing histories, J. Appl. Ecol., 41, 653-663, 2004.

Adler, P. B., Milchunas, D. G., Sala, O. E., Burke, I. C., and Lauenroth, W. K.: Plant traits and ecosystem grazing effects: comparison of US sagebrush steppe and Patagonian steppe, Ecol. Appl., 15, 774-792, 2005.

Anderson, T. M., Ritchie, M. E., and McNaughton, S. J.: Rainfall and soils modify plant community response to grazing in Serengeti National Park, Ecology, 88, 1191-1201, 2007.

Anderson, V. J. and Briske, D. D.: Herbivore-induced species replacement in grasslands - is it driven by herbivory tolerance or avoidance?, Ecol. Appl., 5, 1014-1024, 1995.

Ansquer, P., Duru, M., Theau, J. P., and Cruz, P.: Convergence in plant traits between species within grassland communities simplifies their monitoring, Ecol. Indic., 9, 1020-1029, 2009.

Auerswald, K., Wittmer, M. H. O. M., Männel, T. T., Bai, Y. F., Schäufele, R., and Schnyder, H.: Large regional-scale variation in $\mathrm{C} 3 / \mathrm{C} 4$ distribution pattern of Inner Mongolia steppe is revealed by grazer wool carbon isotope composition, Biogeosciences, 6, 795-805, 2009,

http://www.biogeosciences.net/6/795/2009/.

Bai, Y. F., Zhang, L. X., Zhang, Y., and Chen, Z. Z.: Changes in plant functional composition along gradients of precipitation and temperature in the Xilin River Basin, Inner Mongolia, Acta Phytoecologica Sinica, 26, 308-316, 2002.

Bai, Y. F., Han, X. G., Wu, J. G., Chen, Z. Z., and Li, L. H.: Ecosystem stability and compensatory effects in the Inner Mongolia grassland, Nature, 431, 181-184, 2004.

Bai, Y. F., Wu, J. G., Xing, Q., Pan, Q. M., Huang, J. H., Yang, D. L., and Han, X. G.: Primary production and rain use efficiency across a precipitation gradient on the Mongolia plateau, Ecology, 89, 2140-2153, 2008.

Bai, Y. F., Wu, J. G., Pan, Q. M., Huang, J. H., Wang, Q. B., Li, F. S., Buyantuyev, A., and Han, X. G.: Positive linear relationship between productivity and diversity: evidence from the Eurasian Steppe, J. Appl. Ecol., 44, 1023-1034, 2007.

Bai, Y. F., Wu, J. G., Clark, C. M., Naeem, S., Pan, Q. M., Huang, J. H., Zhang, L. X., and Han, X. G.: Tradeoffs and thresholds in the effects of nitrogen addition on biodiversity and ecosystem functioning: evidence from Inner Mongolia Grasslands, Glob. Change Biol., 16, 358-372, 2010.

Chen, Z. Z.: Topography and climate of Xilin River Basin, in: Research on Grassland Ecosystem, No. 3, edited by: Inner Mongolia Grassland Ecosystem Research Station of Chinese Academy of Sciences, Science Press, Beijing, 13-22, 1988.

Cingolani, A. M., Posse, G., and Collantes, M. B.: Plant functional traits, herbivore selectivity and response to sheep grazing in Patagonian steppe grasslands, J. Appl. Ecol., 42, 50-59, 2005.

Cornelissen, J. H. C., Lavorel, S., Garnier, E., Diaz, S., Buchmann, N., Gurvich, D. E., Reich, P. B., ter Steege, H., Morgan, H. D., van der Heijden, M. G. A., Pausas, J. G., and Poorter, H.: A handbook of protocols for standardised and easy measurement of plant functional traits worldwide, Aust. J. Botany, 51, 335-380, 2003.

Díaz, S., Noy-Meir, I., and Cabido, M.: Can grazing response of herbaceous plants be predicted from simple vegetative traits?, J. Appl. Ecol., 38, 497-508, 2001.

Díaz, S., Lavorel, S., McIntyre, S., Falczuk, V., Casanoves, F., Milchunas, D. G., Skarpe, C., Rusch, G., Sternberg, M., NoyMeir, I., Landsberg, J., Zhang, W., Clark, H., and Campbell, B. D.: Plant trait responses to grazing - a global synthesis, Glob. Change Biol., 13, 313-341, 2007.

Gamfeldt, L., Hillebrand, H., and Jonsson, P. R.: Multiple functions increase the importance of biodiversity for overall ecosystem functioning, Ecology, 89, 1223-1231, 2008.

Garnier, E., Laurent, G., Bellmann, A., Debain, S., Berthelier, P., Ducout, B., Roumet, C., and Navas, M. L.: Consistency of species ranking based on functional leaf traits, New Phytol., 152, 69-83, 2001.

Garnier, E., Lavorel, S., Ansquer, P., Castro, H., Cruz, P., Dolezal, J., Eriksson, O., Fortunel, C., Freitas, H., Golodets, C., Grigulis, K., Jouany, C., Kazakou, E., Kigel, J., Kleyer, M., Lehsten, V., Leps, J., Meier, T., Pakeman, R., Papadimitriou, M., Papanastasis, V. P., Quested, H., Quetier, F., Robson, M., Roumet, C., Rusch, G., Skarpe, C., Sternberg, M., Theau, J. P., Thebault, A., Vile, D., and Zarovali, M. P.: Assessing the effects of land-use change on plant traits, communities and ecosystem functioning 
in grasslands: A standardized methodology and lessons from an application to 11 European sites, Ann. Bot., 99, 967-985, 2007.

Graff, P., Aguiar, M. R., and Chaneton, E. J.: Shifts in positive and negative plant interactions along a grazing intensity gradient, Ecology, 88, 188-199, 2007.

Grime, J. P.: Plant Strategies, Vegetation Processes, and Ecosystem Properties, 2nd edn, John Wiley and Sons, Chichester, 2001.

He, J. S., Wang, X. P., Flynn, D. F. B., Wang, L., Schmid, B., and Fang, J. Y.: Taxonomic, phylogenetic, and environmental trade-offs between leaf productivity and persistence, Ecology, 90, 2779-2791, 2009.

Holechek, J., Pieper, R. D., and Herbel, C. H.: Range Management: Principles and Practices, 5th edn, Pearson Prentice Hall, New Jersey, 2002.

Kleiman, D. and Aarssen, L. W.: The leaf size/number trade-off in trees, J. Ecol., 95, 376-382, 2007.

Klimesova, J., Latzel, V., de Bello, F., and van Groenendael, J. M.: Plant functional traits in studies of vegetation changes in response to grazing and mowing: towards a use of more specific traits, Preslia, 80, 245-253, 2008.

Knapp, A. K., Briggs, J. M., and Koelliker, J. K.: Frequency and extent of water limitation to primary production in a mesic temperate grassland, Ecosystems, 4, 19-28, 2001.

Landsberg, J., Lavorel, S., and Stol, J.: Grazing response groups among understorey plants in arid rangelands, J. Veg. Sci., 10, 683-696, 1999.

Lavorel, S., Grigulis, K., McIntyre, S., Williams, N. S. G., Garden, D., Dorrough, J., Berman, S., Quetier, F., Thebault, A., and Bonis, A.: Assessing functional diversity in the field - methodology matters!, Funct. Ecol., 22, 134-147, 2008.

Li, Y. H.: The divergence and convergence of Leymus chinensis steppe and Stipa grandis steppe under the grazing influence in Xilin River valley, Inner Mongolia, Acta Phytoecologica et Geobotanica Sinica 12, 189-196, 1988.

Loreau, M., Naeem, S., Inchausti, P., Bengtsson, J., Grime, J. P., Hector, A., Hooper, D. U., Huston, M. A., Raffaelli, D., Schmid, B., Tilman, D., and Wardle, D. A.: Biodiversity and ecosystem functioning: current knowledge and future challenges, Science, 294, 804-808, 2001.

McIntyre, S. and Lavorel, S.: Livestock grazing in subtropical pastures: steps in the analysis of attribute response and plant functional types, J. Ecol., 89, 209-226, 2001.

Milchunas, D. G. and Lauenroth, W. K.: Quantitative effects of grazing on vegetation and soils over a global range of environments, Ecol. Monogr., 63, 327-366, 1993.

Mott, K. A., Gibson, A. C., and Oleary, J. W.: The adaptive significance of amphistomatic leaves, Plant Cell Environ., 5, 455-460, 1982.

Naeem, S.: Species redundancy and ecosystem reliability, Conserv. Biol., 12, 39-45, 1998.

Ordonez, J. C., van Bodegom, P. M., Witte, J. P. M., Wright, I. J., Reich, P. B., and Aerts, R.: A global study of relationships between leaf traits, climate and soil measures of nutrient fertility, Glob. Ecol. Biogeogr., 18, 137-149, 2009.

Osem, Y., Perevolotsky, A., and Kigel, J.: Site productivity and plant size explain the response of annual species to grazing exclusion in a Mediterranean semi-arid rangeland, J. Ecol., 92, 297309, 2004

Pérez-Harguindeguy, N., Díaz, S., Vendramini, F., Cornelissen, J.
H. C., Gurvich, D. E., and Cabido, M.: Leaf traits and herbivore selection in the field and in cafeteria experiments, Austral Ecol., 28, 642-650, 2003.

Page, A. L., Miller, R. H., and Keeney, D. R.: Methods of Soil Analysis, Part 2: Chemical and Microbiological Properties, 2nd edn, American Society of Agronomy Press, Madison, 1982.

Pakeman, R. J.: Consistency of plant species and trait responses to grazing along a productivity gradient: a multi-site analysis, $\mathrm{J}$. Ecol., 92, 893-905, 2004.

Quested, H., Eriksson, O., Fortunel, C., and Garnier, E.: Plant traits relate to whole-community litter quality and decomposition following land use change, Funct. Ecol., 21, 1016-1026, 2007.

Reich, P. B., Wright, I. J., and Lusk, C. H.: Predicting leaf physiology from simple plant and climate attributes: a global GLOPNET analysis, Ecol. Appl., 17, 1982-1988, 2007.

Reich, P. B., Ellsworth, D. S., Walters, M. B., Vose, J. M., Gresham, C., Volin, J. C., and Bowman, W. D.: Generality of leaf trait relationships: A test across six biomes, Ecology, 80, 1955-1969, 1999.

Ren, H. Y., Zheng, S. X., and Bai, Y. F.: Effects of grazing on plant biomass allocation of six grassland communities in Xilin River Basin, Inner Mongolia, Chinese J. Plant Ecol., 33, 1065-1074, 2009.

Rusch, G. M., Skarpe, C., and Halley, D. J.: Plant traits link hypothesis about resource-use and response to herbivory, Basic Appl. Ecol., 10, 466-474, 2009.

Sala, O. E., Parton, W. J., Joyce, L. A., and Lauenroth, W. K.: Primary production of the central grassland region of the United States, Ecology, 69, 40-45, 1988.

Schumacher, J. and Roscher, C.: Differential effects of functional traits on aboveground biomass in semi-natural grasslands, Oikos, 118, 1659-1668, 2009.

Semmartin, M., Garibaldi, L. A., and Chaneton, E. J.: Grazing history effects on above- and below-ground litter decomposition and nutrient cycling in two co-occurring grasses, Plant Soil, 303, 177-189, 2008.

Semmartin, M., Aguiar, M. R., Distel, R. A., Moretto, A. S., and Ghersa, C. M.: Litter quality and nutrient cycling affected by grazing-induced species replacements along a precipitation gradient, Oikos, 107, 148-160, 2004.

Shipley, B.: Structured interspecific determinants of specific leafarea in 34 species of herbaceous angiosperms, Funct. Ecol., 9, 312-319, 1995.

Vesk, P. A. and Westoby, M.: Predicting plant species' responses to grazing, J. Appl. Ecol., 38, 897-909, 2001.

Vesk, P. A., Leishman, M. R., and Westoby, M.: Simple traits do not predict grazing response in Australian dry shrublands and woodlands, J. Appl. Ecol., 41, 22-31, 2004.

Violle, C., Navas, M. L., Vile, D., Kazakou, E., Fortunel, C., Hummel, I., and Garnier, E.: Let the concept of trait be functional!, Oikos, 116, 882-892, 2007.

Wardle, D. A., Barker, G. M., Bonner, K. I., and Nicholson, K S.: Can comparative approaches based on plant ecophysiological traits predict the nature of biotic interactions and individual plant species effects in ecosystems?, J. Ecol., 86, 405-420, 1998.

Warren, C. R. and Adams, M. A.: Trade-offs between the persistence of foliage and productivity in two Pinus species, Oecologia, 124, 487-494, 2000.

Westoby, M., Falster, D. S., Moles, A. T., Vesk, P. A., and Wright, 
I. J.: Plant ecological strategies: some leading dimensions of variation between species, Annu. Rev. Ecol. Syst., 33, 125-159, 2002.

Wilson, P. J., Thompson, K., and Hodgson, J. G.: Specific leaf area and leaf dry matter content as alternative predictors of plant strategies, New Phytol., 143, 155-162, 1999.

Wright, I. J., Reich, P. B., Westoby, M., Ackerly, D. D., Baruch, Z., Bongers, F., Cavender-Bares, J., Chapin, T., Cornelissen, J. H. C., Diemer, M., Flexas, J., Garnier, E., Groom, P. K., Gulias, J., Hikosaka, K., Lamont, B. B., Lee, T., Lee, W., Lusk, C., Midgley, J. J., Navas, M. L., Niinemets, U., Oleksyn, J., Osada, N., Poorter, H., Poot, P., Prior, L., Pyankov, V. I., Roumet, C., Thomas, S. C., Tjoelker, M. G., Veneklaas, E. J., and Villar, R.: The worldwide leaf economics spectrum, Nature, 428, 821-827, 2004.
Zheng, S. X. and Shangguan, Z. P.: Spatial patterns of photosynthetic characteristics and leaf physical traits of plants in the Loess Plateau of China, Plant Ecol., 191, 279-293, 2007.

Zheng, S. X., Lan, Z. C., Li, W. H., Shan, Y. M., Wan, H. W., Taube, F., and BaI, Y. F.: Differential responses of plant functional trait to grazing between two contrasting dominant $C_{3}$ and $C_{4}$ species in a typical steppe, Plant Soil, accepted, 2010. 